\title{
New supplementation proposals for pregnant women with foetal cardiac diseases
}

\author{
Julia Murlewska', Magdalena Szlagor², Maria Respondek-Liberska' ${ }^{1,3}$ \\ 1Prenatal Cardiology Department, Research Institute, Polish Mother's Memorial Hospital, Lodz, Poland \\ ${ }^{2}$ Student's Prenatal Cardiology Team, Medical University of Lodz, Lodz, Poland \\ ${ }^{3}$ Department for Foetal Malformations Diagnoses and Prevention, Medical University of Lodz, Lodz, Poland
}

\begin{abstract}
Should we pay special attention to the supplementation for patients with a congenital foetal heart defect, whether they require special care, assuming that each subsequent pregnancy should be planned? Should patients with cardiac problems in their current pregnancy make any changes to their regular supplementation? In our short report we would like to discuss the issues of supplementation, especially folates and vitamin D, from the perspective of prenatal cardiology and specific problems affecting postnatal prognosis, paying special attention to the prevention of COVID-19 and pre-eclampsia during pregnancy. We propose that our observations be considered concerning mainly rich supplementation with folic acid as well as vitamin $\mathrm{D}$ for patients with cardiac problems in the foetus.
\end{abstract}

Key words: congenital heart defect, fetal cardiac dysfunction, folates, vitamin D, COVID-19, infections in pregnancy, preeclampsia.

Corresponding author: Dr. Julia Murlewska, Prenatal Cardiology Department, Research Institute, Polish Mother's Memorial Hospital, Lodz, Poland, e-mail: juliamurlewska.jm@gmail.com

Generally, we can state that supplementation during pregnancy with folic acid, iodine, and vitamin $\mathrm{D}$ and docosahexaenoic acid (DHA) are necessary. This is directly due to the scientifically proven increase in demand for these supplements during pregnancy, as well as to the widespread shortage among pregnant women and the difficulty of supplementing them with a balanced diet that would then be too calorific, even for a pregnant woman. Other ingredients such as iron, calcium, choline, zinc, and vitamin $\mathrm{C}$ should only be used according to individual needs during pregnancy. Pregnancy supplementation has many beneficial effects: it can prevent the occurrence of birth defects in the foetus and has a beneficial effect on the occurrence of growth disorders, pre-eclampsia, premature births, or infections in pregnant women [1].
The most scientifically documented link between the occurrence of congenital malformations and supplementation during pregnancy concerns folates. The role of folic acid in reducing foetal neural tube defects has been scientifically proven through numerous meta-analyses and randomised studies. Due to the very common occurrence of polymorphisms of the MTHFR gene (methylenetetrahydrofolate reductase), and therefore frequent folic acid absorption disorders, which may affect up to $50 \%$ of the white population, we should choose, in addition to folic acid, preparations containing metafolin for patients planning to get pregnant, at least for 3 months, at a dose of $400 \mu \mathrm{g}$. During pregnancy each patient should use $800 \mu \mathrm{g} /$ day of folates (including $400 \mu \mathrm{g}$ of folic acid and $400 \mu \mathrm{g}$ of metafolin); this is primarily due to the high percentage of unplanned preg- 
Table I. Proposal for supplementation for pregnant women with foetal cardiac diseases [1]

\begin{tabular}{|l|l|}
\hline Daily dose & \multicolumn{1}{c|}{ Recommendations } \\
\hline $800 \mu \mathrm{g}$ folic acid $+400 \mu \mathrm{g}$ metafolin $=$ & $\begin{array}{l}\text { All women planning to get pregnant, pregnant, and breastfeeding (due to the high } \\
\text { percentage of unplanned pregnancies, late implementation of supplementation, most often } \\
\text { only after obtaining a positive pregnancy test result, as well as common MTHFR mutation) }\end{array}$ \\
\hline $4 \mathrm{mg} /$ day folic acid & $\begin{array}{l}1 \mathrm{month} \text { before pregnancy and the first } 3 \text { months in pregnancy, later followed by a dose of } \\
800 \mathrm{mg} / \text { day of folate in pregnancy and for breastfeeding patients } \\
\text { - for patients who have had a pregnancy complicated by an NTD } \\
\text { - for patients who have had a pregnancy complicated by a CHD??? }\end{array}$ \\
\hline $4000 \mathrm{IU} /$ day vitamin D & $\begin{array}{l}\text { All women planning to get pregnant, pregnant, and breastfeeding } \\
\text { Pregnant women with: } \\
\text { - chronic kidney disease } \\
\text { - vitamin D-dependent rickets } \\
\text { - cancer-induced osteomalacia } \\
\text { - BMl > } 30 \mathrm{~kg} / \mathrm{m}^{2} \\
\text { - CHD complicated by maternal infection: upper respiratory tract infection, urinary and } \\
\text { genital tract infection??? } \\
\text { - CHD complicated by heart failure in the risk of preeclampsia??? }\end{array}$ \\
\hline
\end{tabular}

nancies, late implementation of supplementation, most often only after obtaining a positive pregnancy test result, as well as the above-mentioned common MTHFR mutation. The $4 \mathrm{mg}$ /day dose of folic acid is intended only for patients with a positive history of neural tube defect (NTD) in a foetus in a previous pregnancy (and only 1 month before pregnancy plus the first 12 weeks of pregnancy, then the dose is reduced to $800 \mathrm{mcg} / \mathrm{day}$ ), in accordance with the recommendations of the Polish Society of Gynaecologists and Obstetricians (Table I). Prolonged use of folic acid at a dose of $4 \mathrm{mg} /$ day may be associated with an increased risk of autism, asthma, and insulin resistance in children, which is also reported in medical publications [1].

The embryogenesis of the cardiovascular system is a complex and multistage process, which takes place between 2 and 7 weeks of gestation [2]. Heart defects are among the

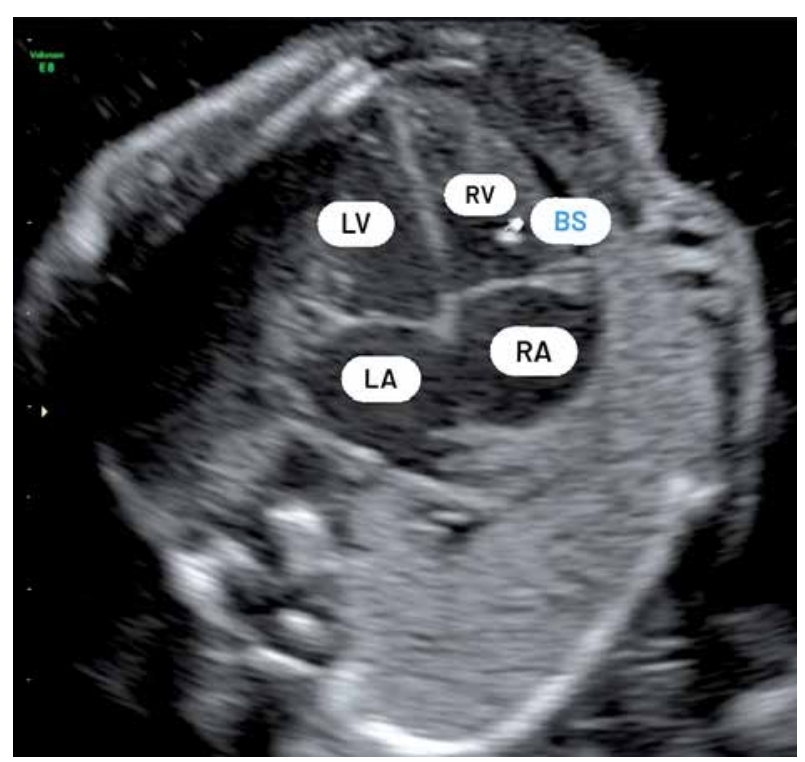

Figure 1. 4CV-four chamber view of the foetal heart in the course of maternal urogenital tract infection; in the right ventricle we see BS - bright spot; LV - left ventricle; LA - left atrium; RV right ventricle; RA - right atrium most common congenital defects in humans, and low concentrations of folic acid, hyperhomocysteinaemia, and MTHFR polymorphisms are also very common in children with congenital heart defects and their mothers. The relationship between mutations of the MTHFR gene and the occurrence of congenital heart defects in children has also been proven $[3,4]$. Should we also consider increasing the standard dose of $400 \mu \mathrm{g}$ of folic acid for patients who have given birth to a child with a congenital heart defect, analogous to the recommendations prepared for families with a positive history of NTD (Table I) [1]? It seems that patients with a previous pregnancy accompanied by a congenital foetal defect could also benefit from a higher dose of folic acid supplementation. However, there are fewer meta-analyses and randomised studies, which could prove the same strong role of folic acid in reducing congenital heart defects as was proven in neural tube defects. This is probably also related to the use of rather standard low doses of folic acid and suboptimal supplementation time before and during pregnancy in recent studies for pregnant patients with a history of CHD [5].

Another essential element in supplementation during pregnancy is vitamin D. During pregnancy, women with no burdens suggesting a deficit of vitamin D (chronic kidney disease, vitamin D-dependent rickets, cancer-induced osteomalacia) and a normal body mass index (BMI) should follow supplementation of 2000 IU vitamin D per day. Women who have BMI $>30 \mathrm{~kg} / \mathrm{m}^{2}$ have a particularly high risk of vitamin $\mathrm{D}$ deficiency (Table I). Their diet is considered to contain no or too little vitamin $\mathrm{D}$. The studies conducted so far have not shown any adverse effect of vitamin D supplementation during pregnancy to the dose of 4000 IU/day [1]. The results showed a significant decrease in maternal serum vitamin D level among mothers who had term neonates with CHD [6], and associations between maternal viral infection in general may play an important role in the occurrence of CHD [7]. Women with vitamin D deficiency are at increased risk of urinary tract infections (UTIs) during pregnancy. Vitamin D affects the mucous membrane of the urinary bladder, showing immunomodulatory ability to prevent bacte- 
rial infection. Vitamin D deficiency was found in $85.7 \%$ of pregnant women with symptomatic urinary tract infections [8]. Moreover, scientific evidence confirms the negative correlation between serum concentrations of vitamin $\mathrm{D}$ and bacterial vaginosis (BV) during pregnancy [9]. The efficacy of vitamin D supplementation in pre-eclampsia prevention has also been confirmed and was, for vitamin D supplementation alone (47.4\%), for calcium only (31.6\%), and for calcium plus vitamin D supplementation (19.6\%) [10].

So, should we recommend higher doses of $4000 \mathrm{IU} /$ day of vitamin $\mathrm{D}$ for patients with a past pregnancy complicated by a congenital foetal heart defect? Would supplementation with an increased dose of vitamin $\mathrm{D}$ also be beneficial in cases of symptomatic infections of the respiratory tract, like COVID-19 or urogenital tract infection, which is so common during pregnancy, especially if we see the foetal response to a maternal infection, such as foetal cardiac calcifications or BS-bright spots (Figure 1)? Finally, would high doses of vitamin $\mathrm{D}$ be worth supplementing in patients with CHD complicated by maternal-foetal infections, especially in the course of foetal circulatory failure, in view of the risk of pre-eclampsia [2]? Therefore, we propose consideration of our observations concerning mainly rich supplementation with folic acid as well as vitamin D for patients with cardiac problems in the foetus.

\section{Conflict of interest}

The authors declare no conflict of interest.

\section{References}

1. Zimmer M, Sieroszewski P, Oszukowski P, et al. Rekomendacje Polskiego Towarzystwa Ginekologów i Położników dotyczące suplementacji u kobiet ciężarnych. 2020; 7: 1-21.

2. Ojala TH, Hornberger LK. Fetal heart failure. Front Biosci 2010; 2: 891-906.

3. Wang D, Zhang Y, Jiang Y, et al. Shanghai Preconception Cohort (SPCC) for the association of periconceptional parental key nutritional factors with health outcomes of children with congenital heart disease: a cohort profile. BMJ Open 2019; 9: e031076.

4. Obeid R, Holzgreve W, Pietrzik K. Folate supplementation for prevention of congenital heart defects and low birth weight: an update. Cardiovasc Diagn Ther 2019; 9 (Suppl 2): S424-33.

5. Øyen N, Olsen SF, Basit S, et al. Association between maternal folic acid supplementation and congenital heart defects in offspring in birth cohorts from Denmark and Norway. J Am Heart Assoc 2019; 8: e011615.

6. Mokhtar WA, Fawzy A, Allam RM, et al. Maternal vitamin D level and vitamin $\mathrm{D}$ receptor gene polymorphism as a risk factor for congenital heart diseases in offspring; an Egyptian case-control study. Genes Dis 2018; 6: 193-200.

7. Liang $\mathrm{Q}$, Gong $\mathrm{W}$, Zheng D, et al. The influence of maternal exposure history to virus and medicine during pregnancy on congenital heart defects of fetus. Environ Sci Pollut Res Int 2017; 24: 5628-32.

8. Haghdoost S, Pazandeh F, Darvish S, et al. Association of serum vitamin $\mathrm{D}$ levels and urinary tract infection in pregnant women: a case control study. Eur J Obstet Gynecol Reprod Biol 2019; 243: $51-6$.
9. Jefferson KK, Parikh HI, Garcia EM, et al. Relationship between vitamin $\mathrm{D}$ status and the vaginal microbiome during pregnancy. J Perinatol 2019; 39: 824-36.

10. Khaing W, Vallibhakara SA, Tantrakul V, et al. Calcium and vitamin D supplementation for prevention of preeclampsia: a systematic review and network meta-analysis. Nutrients 2017; 9: 1141. 